\title{
Wittgenstein and the unity of good
}

Oskari Kuusela; o.kuusela@uea.ac.uk; EJP-19-135.R1

School of Politics, Philosophy, Language and Communication Studies, University of East Anglia, ARTS Building, University of East Anglia, Norwich, NR4 7TJ

\begin{abstract}
This paper discusses the problem of the unity of moral good, concerning the kind of unity that moral good or the concept thereof constitutes. In particular, I am concerned with how Wittgenstein's identification of various complex modes of conceptual unity, and his introduction of a methodology of clarification for dealing with such complex concepts, can help with the problem of unity, as it rises from the moral philosophical tradition. Relating to this I also address the disputed question, whether Wittgenstein regards good as a family-resemblance concept, and make an attempt to characterize family-resemblance concepts generally by way of their similarities and differences from certain other complex modes of conceptual unity. I argue that whilst Wittgenstein does regard good as a familyresemblance concept, in the Philosophical Investigations he seeks to make a more general methodological point. I conclude with a suggestion of how Wittgenstein's methodological points can help us to put into a broader perspective famous criticisms of the moral philosophical tradition by Michael Stocker and Bernard Williams, and how Wittgenstein's methods more generally can help to address the problem of the unity of good. This illustrates one way in which Wittgensteinian methods can help resolve disputes in moral philosophy, where the main approaches, Aristotelian, Kantian and utilitarian theories, seem to be locked in a stalemate. As I argue, this situation has to do with their assumptions about the unity of moral good. The response isn't to reject those theories, however, but to re-interpret them in a way consistent with the Wittgensteinian methodology.
\end{abstract}




\section{Introduction}

The topic of this article is the problem of the unity of moral good, concerning the kind of unity that moral good or the concept thereof constitutes. In particular, I am concerned with how Wittgenstein's identification of various complex modes of conceptual unity, and his introduction of a methodology for dealing with such complex concepts, can help with the problem of the unity of good, as it arises from the moral philosophical tradition and assumptions made therein. Relating to this, I also address the disputed question, whether Wittgenstein regards good as a family-resemblance concept, and make an attempt to characterize family-resemblance concepts generally by way of their similarities and differences from certain other complex modes of conceptual unity. I argue that whilst it's not Wittgenstein's purpose in the Philosophical Investigations to make any claims about the familyresemblance character of the concept of moral good, but rather to introduce a method for dealing with concepts with complex unity more generally, he does regard moral good as a family-resemblance concept, as testified by his remarks elsewhere. Although exegetical questions cannot be avoided in this connection, they are not the point, but rather the problem of the unity of good, i.e. how we might address it and the more specific philosophical difficulties to which it gives rise. I conclude with a suggestion about how Wittgenstein's methodology in the Investigations can help us to put into broader perspective famous criticisms of the moral philosophical tradition by Michael Stocker and Bernard Williams. This is meant to illustrate one way in which Wittgensteinian methods can help resolve disputes in moral philosophy, where the main approaches, Aristotelian, Kantian and utilitarian theories, seem to be locked in a stalemate. As I argue, this situation has to do with their assumptions about the unity of moral good. The response isn't to reject those theories, however. It's to re-interpret them in a way consistent with the Wittgensteinian methodology.

\section{Accounts of the unity of good in the philosophical tradition}


Aristotle observes at the beginning of Nicomachean Ethics that "good is spoken of in as many senses as is being", namely, in the categories of substance, quality, quantity, relationship, time and location. Part of his point is to put pressure on Plato or his followers, that is, "those who introduced the forms", with Aristotle going on to remark that "So it is clear that there could not be one common universal, because it would not be spoken of in all categories, but only one.” (NE p. 1096a; cf. EE Book I, Chapter VIII) Naturally, Aristotle is aware that his argument leaves room to counter moves, such as distinguishing between things that are good in themselves and things that are good for the sake of things good in themselves, and maintaining that only the former are called "good" with reference to a common universal or the form of good. Nevertheless, as Aristotle points out, on this account all things that are good in themselves should still have the same universal definition, and this doesn't seem to be the case. "But the definitions of honour, practical wisdom, and pleasure are distinct, and differ with respect to their being good. There is therefore no common good answering to a single Form." (NE p. 1096b)

Plato's followers thus are not released from the difficulty, but owe an explanation how the postulation of the form of good helps to understand the unity that underlies the apparent diversity of instances of goodness. How does the form help to better grasp what is good in individual cases and clarify the relations between different instances of goodness? How can goodness in this abstract sense constitute the end of actions, given that the postulated form of good is something distinct from empirical phenomena, and how does the comprehension of the form help us to understand what we ought to do? Without answers to these questions, the Platonic account doesn't seem helpful with the regard to understanding the unity of good, given that the variety which the different instances of good exhibit is clearly not merely a matter of ambiguity. "But how, then, are things called good? For they do not seem like items that have the same name by chance." (NE p. 1096b) ${ }^{1}$

What possible ways are there to answer the question regarding the unity of good? Following his critique of Plato and Plato's followers Aristotle lists the remaining options as follows: "Is it through all 
[instances of good] deriving from one good, or their all contributing to one good, or is it rather by analogy?” (NE p. 1096b; my square brackets) Aristotle's own explanation of the unity of good, I take it, conforms to the first option. Different cases of good are regarded as good due to their deriving from virtue, i.e. a state of excellence of the soul, or by contributing to one good, the highest good of eudaimonia, i.e. to the good life which virtue makes possible. (Unlike Socrates and the Stoics, Aristotle doesn't consider virtue sufficient for eudaimonia, but it requires external goods too, virtuously used.) $)^{2}$ The contributory model that is part of Aristotle's account, and according to which goodness of actions and other goods consists in the contribution to some highest good, has proven attractive to others too. It's adopted, for example, by Ancient hedonists and modern utilitarians. For even if the utilitarian account of the good is crucially different from Aristotle, utilitarians nevertheless explain goodness in terms of the contribution of actions, character traits, and so on, to the good of utility, regarded as the highest good and only thing good in itself. (Mill, 1998 p. 115)

Considering the possible ways of explaining goodness as outlined by Aristotle, we might also include Kant on the list of Plato's followers. Although this might at first sight seem odd, the basic affinity is evident. Similarly to Plato, Kant seeks to explain the unity underlying the diverse cases of moral goodness in terms of a non-empirical principle, the moral law, which our comprehension of anything as morally good or bad/evil is derived from. Thus, just as for Plato the form constitutes the basis for distinguishing between good and bad/evil and classifying empirically given cases accordingly, so the moral law constitutes the basis of our comprehension of the distinction between good and bad/evil for Kant. Only in this way, Kant maintains, can the distinction be saved from the contingencies of customs and preferences, and the unconditional or absolute character of good and bad/evil explained (Kant, 1997 p. 4:389). Indeed, the way in which Kant develops the derivative model seems to provide us with a rather promising way to answer Aristotle's question of how an abstract notion of goodness could help to grasp empirically given cases. It can help us by reminding us, for example, of the importance of asking whether a case might be one in which we take unfair advantage of others or 
institutions in which we partake, thus failing to act so that the maxim of our action could become a universal law, and by reminding us of the importance of considering whether we are failing to respect others as end-setting rational beings. Crucially, unlike Plato, Kant does give the underlying principle specific formulations, rather than merely assuming that there must be such a principle without formulating it. By contrast to Kant, Plato's failure to give any formulation for the postulated principle seems to leave his account empty, and consequently vulnerable to Aristotle's challenges.

Both the contributory model and the derivative model of the unity of good can therefore be developed in interesting ways. It's not obvious which one we should adopt, and whether Aristotle's own account is to be preferred. Whether any conclusive grounds can be given for adopting one model rather than the other, is a difficult question. Historically, none of the parties have managed to convince the others of the benefits of their own model, and it seems fair to say that by now the Aristotelian, Kantian and utilitarian approaches have reached a stalemate, where they stay locked in their positions, unlikely to gain an argumentative upper hand over the others. This gives rise to the question, why this is the case, and whether this outcome has something to do with the fact that both the derivative and contributory models assume good to possess a simple unity that can be explained with reference to something common to all instances of goodness. Would it be possible to make progress on the question of the unity of good by questioning this shared assumption?

A different kind of account of unity is given by the explanation in terms of analogies, the last option on Aristotle's list. This account comes across as a non-starter, however, at least on certain ways of taking it. As G. H. von Wright observes, the unity of goodness doesn't seem explainable by way of analogy in that, while analogical explanations assume a primary meaning/sense as the basis of analogical extensions, good doesn't seem to fit this model. In the case of good there doesn't seem to be a primary meaning/sense, corresponding to the primary sense in which, for example, a sea or cave can be deep, as opposed to someone being deep in thought. What would this primary sense be and what are its analogical extensions? The difficulty of identifying anything like this indicates that the unity of good 
isn't based on analogies (von Wright, 1963 p. 15). Indeed, this structure of primary sense and extensions seems to hold even in the case of so-called dead metaphors, where there is no nonmetaphorical way of expression, as in the case of a leg of a table and mouth of a river. Now, perhaps this doesn't exclude the possibility that some uses of "good" would constitute analogical extensions of some more primary senses that may be regarded as primary in relation to the analogical extensions in question (von Wright, 1963 p. 15). But this isn't the same as explaining all other instances of goodness with reference to a certain primary meaning/sense. ${ }^{3}$

In this way we are led back to the question of the unity and whether questioning the assumption of simple conceptual unity (definability with reference to something common to all instances) might help to address the problem. Let us now turn to what Wittgenstein says about the unity of good.

\section{Wittgenstein on good in the Investigations}

Wittgenstein's remarks on the unity of good have been a topic of some dispute. While von Wright (1963 p. 16) and Peter Hacker (2005 p. 171) have argued that Wittgenstein doesn't regard good as a family-resemblance concept, or if he does he ought not to, the interpretation that Wittgenstein does regard good as a family-resemblance concept has been recently defended by James Klagge (2018) ${ }^{4}$. Textual evidence for settling the question is mostly indirect, however, and even Wittgenstein's most direct remarks on this issue require interpretation. Consequently, because he doesn't state very clearly in the Investigations, Nachlass or lectures that good is a family resemblance concept, the argument between von Wright, Hacker and Klagge partly depends on questions relating to the characteristics of family-resemblance concepts, and whether the concept of good behaves like family-resemblance concepts generally do: whether, for example, new kind of cases can be added to the extension of the concept, and whether there are disputed cases - as in the case of art, for example (von Wright, 1963 16; Hacker, 2005 p. 171). Given these complexities, it seems best to first examine what Wittgenstein 
understands by a family-resemblance concept, and what is going on in the contexts where Wittgenstein makes his remarks on good, rather than trying to directly settle the interpretative argument. This is what I will do, beginning with a discussion of Wittgenstein's remark on good and its context in the Investigations. I will return to the dispute later.

Perhaps the most authoritative suggestion that the later Wittgenstein understands good as a family-resemblance concept is found in the Investigations, given the authoritative status of this work among his writings. As the examination of this remark and its context reveals, however, it only constitutes indirect evidence for Wittgenstein's regarding good as a family-resemblance concept. Rather than concerned to make a point about good as such, in the relevant remark Wittgenstein seems to be developing a more general methodological point about how to deal in philosophy with concepts that lack simple unity, i.e. have no common defining feature, including concepts with blurred boundaries, such as family-resemblance concepts ${ }^{5}$, and concepts with fluctuating use. Let us look into this more closely.

Wittgenstein's comments on good in the Investigations occur in a remark that concerns the possibility of defining concepts with blurred boundaries, and the possibility of using definitions to clarify such blurred concepts. Evidently, he intends such blurred concepts to include familyresemblance concepts with open boundaries, but it's equally clear that family-resemblance concepts are only one kind of example of blurred concepts. (I return to this shortly.) Ethics and aesthetics are then referred to as examples of discourses with blurred concepts, and as examples of contexts where the difficulty arises of finding definitions that correspond to the concepts. Good specifically is mentioned an example in order to illustrate what we should do in such a case. Wittgenstein writes:

And if we carry this comparison [between a concept with an explicit definition and a sharply bound drawing and an undefined concept and a blurred picture] still further it is clear that the degree to which the sharp picture can resemble the blurred one depends on the degree to which the latter lacks sharpness. For imagine having to sketch a sharp picture 'corresponding' to a blurred one. In the latter there is a blurred red rectangle; you replace it with a sharp one. Of course - 
several such sharply delineated rectangles can be drawn to correspond to the blurred one. - But if the colours in the original shade into one another without a hint of any outline won't it become a hopeless task to draw a sharp picture corresponding to the blurred one? Won't you then have to say: "Here I might just as well draw a circle as a rectangle or a heart, for the colours merge. Anything - and nothing - is right."- And this is the position in which, for example, someone finds himself in ethics or aesthetics when he looks for definitions that correspond to our concepts.

In this sort of predicament always ask yourself: How did we learn the meaning of this word ("good" for instance)? From what sort of examples? In what language-games? Then it will be easier for you to see that the word must have a family of meanings. (PI §77; my square brackets; cf. MS 142 p. 66; TS 220 p. 57)

From a logical or methodological point of view, one might perhaps suspect the last paragraph for committing the genetic fallacy, where one falsely infers from how the use of a word is learned to characteristics of its fully developed use. Reasons of charity of interpretation, however, preclude the attribution of such a mistake to Wittgenstein, if there is an alternative. Instead, his point can be understood as a heuristic and methodological one, concerning difficulties that may arise in connection with finding and articulating definitions. On this interpretation he is saying that, when faced with the difficulty of giving definitions that correspond to our concepts, we should consider how the use of relevant locutions is learned: through which examples and language-games, are children introduced to the uses of "good" in the moral sense? ${ }^{6}$ When we consider this question, Wittgenstein suggests, it will be easier to see that the difficulty of finding an adequate definition is - or "must be" in a heuristic sense - due to our problematically assuming that the word is used in one language-game only, and that there ought to be a single definition corresponding to it. Note that by a concept Wittgenstein understands here something that finds its expression in the use(s) of relevant word(s), and thus something that can be clarified by examining relevant uses. The language-games in which children learn the use of relevant word(s) are then of particular interest because of their simplicity, which allows us to see the different kind of uses, or some basic forms thereof, more easily than if we were to examine their fully developed use as a whole. (PI $\S \S 5,7$; Kuusela 2014 and 2019b, Chapter 5 discuss the method of language-games.) 
Wittgenstein's heuristic suggestion can be summed up as follows. In case of a failure to find a definition, check whether the concept might have a family of meanings or uses, an indication for which is how its use is learned. If such multiplicity is found, this gives a reason to think that there might not be any single definition that corresponds to the concept (cf. AWL p. 33, quoted in section 4). Indeed, this point seems well worth making in that a philosopher might well regard a failure to find a definition as merely indicating that we must look further and/or work harder on proposed definitions. Wittgenstein's suggestion therefore provides an alternative to this more standard philosophical response. Sometimes the right thing might be to change tack, instead of assuming that there must be an overarching definition.

Read in this way, Wittgenstein's comment on good then isn't an assertion about the unity of good which he doesn't even attempt to justify. Although this doesn't exclude Wittgenstein's regarding good as a family-resemblance concept, it means that $§ 77$ offers no more than indirect evidence for the attribution that Wittgenstein does regard it so. ${ }^{7}$ Another important feature of this interpretation is that it anchors the remark on good in the context of discussion in the Investigations. As I argue below, attending to this context is crucial for a proper grasp of Wittgenstein's point.

The context of Investigations $\S 77$ can be briefly outlined as follows: remarks $\S \S 65-83$ raise questions about the possibility of clarificatory use of definitions, or more broadly about the possibility of describing language as a game according to rules. This then leads, after a few comments on rules and exactness in $\S \S 84-88$, to the discussion the philosophy of logic and philosophical methodology in $\S \S 89-132$ for which $\S \S 65-88$ provide an important background. Since not all remarks between $\S \S 65-88$ concern family-resemblance, but also other kinds of concepts whose use isn't regulated by a definite rules or not overall regulated by rules, and in connection with which the same methodological questions arise concerning the employment of rules in philosophical clarification, it's useful next to take a closer look at $\S \S 65-83$. This helps to further clarify Wittgenstein's point in $\S 77$, the relevant 
methodological issues, and how family-resemblance concepts relate to other not sharply bound concepts.

\section{Wittgenstein's methodological points in Investigations $\$ \$ 65-83$}

Remarks $\S \S 65-83$ start with the introduction of the notion of family-resemblance and Wittgenstein's admission that he isn't looking for anything common to all instances of language that constitutes their common essence, in contrast to his search for the general form of proposition in the Tractatus (see TLP $4.5,5,5.47-5471)$. According to him, it's not because of anything common to all instances of language that we call them all "language", but because they are akin to one another in various ways, a point which he then seeks to clarify by using the less controversial case of games as his example (PI §65-66). Wittgenstein concludes: "And the upshot of these considerations is: we see a complicated network of similarities overlapping and criss-crossing: similarities in the large and in the small.” (PI §66) Further, Wittgenstein describes kinds of number as constituting a family, whereby some number kinds are called "numbers" because of their direct relationship with what we have called "number" up to now, and further cases because of their indirect relation to the more basic cases. (PI §67) But would this not mean that the concept of number is defined as the logical sum of number kinds, asks Wittgenstein's interlocutor? Wittgenstein responds: “[...] I can give the concept 'number' rigid boundaries in this way, that is, use the word "number" for a rigidly bounded concept, but I can also use it so that the extension of the concept is not closed by a boundary." (PI §68) As he then goes on to argue by means of examples and analogous cases, this openness of boundaries doesn't mean that the use of "game" or “number" wouldn’t be regulated by any rules (PI §68). Neither is it the case that we don't really know what a game or a number is before we give a definition (PI §70), or that such a blurred concept isn't really a concept (PI §71). Thus, while we can draw sharp boundaries to concepts, this isn't in general a condition for their adequacy or for the possibility of their use. What we are faced with isn't ignorance 
of conceptual boundaries, but that such boundaries have not been drawn (PI §69). Instead, such concepts can be explained, for instance, by means of examples, whereby examples are used in a specific way, but not to indicate something common to all cases (PI §71).

After a small digression to what it is to see something as being common to different cases, or to see something as an example (PI $\S \S 74-75)$, Wittgenstein comes to his comparison between blurred and sharp pictures and blurred and defined concepts, noting that, while a concept with a sharp boundary isn't the same as a blurred concept for which one doesn't wish to draw no boundary, the two are akin to one another (PI §76). ${ }^{8}$ Next, following $\S 77$ (quoted earlier), he pauses briefly in $\S 78$ to raise the question, whether knowing something is always a matter of being able to say what one knows illustrated by three examples: how high Mont Blanc is, how the word "game" is used, and how a clarinet sounds. Again Wittgenstein doesn't develop this point, beyond suggesting that whoever claims knowing means being able to say probably has in mind a case like the first example, not like the last one. Possibly "game" could then be seen as an intermediate case between the two clearer ones. But without elaborating on this Wittgenstein moves on to discuss a concept markedly different from familyresemblance concepts, the name "Moses". Let me next explain how this concept and the one discussed after Moses differ from family-resemblance concepts, and then continue to follow how Wittgenstein develops his methodological point.

What Wittgenstein says about Moses can be summarized as follows. "Moses" could be given a variety of definitions, as exemplified by different Russellian definite descriptions that could be used to define it. While the meaning of sentences involving "Moses" would correspondingly vary depending on the definition, there is no particular definition that could be privileged, Wittgenstein says, thus rejecting Russell's view of the meaning of a name as equivalent to some definite description. Neither is there, according to Wittgenstein, a clear limit to how much of what one understands by Moses should be true or false in order for one to have to regard the sentence "Moses did exists" as false. The meaning of the name is therefore not definable as a conjunction of definite descriptions either. Next, 
Wittgenstein asks suggestively, is it not that rather than the name having a "fixed and unequivocally determined use" for me, I have a "whole series of supports in readiness" so that I "am ready to lean on one if another should be taken from under me" (PI §79)? Or as he contends with reference to another similar example of a person name, 'I use the name "N" without a fixed meaning.' (PI §79) But as he again emphasizes, this doesn't impair its use any more than a four-legged table is unusable, as opposed to a three-legged one, because it occasionally wobbles.

$\S 79$ is immediately followed by a different example of the use of a word which isn’t regulated by rules overall in that we don't have rules for all conceivable occasions of its use. ${ }^{9}$ Here Wittgenstein imagines a chair that keeps mysteriously disappearing and reappearing, making a related but not the same point as about "Moses". As he explains, although such behaviour of a chair would indeed create confusion as to whether the object can be referred to as a chair, this doesn't make the word "chair" meaningless in general. The problem is contained in that the absence of rules for such peculiar occasions doesn't affect the word's use in other more usual contexts, as the questions Wittgenstein raises in the remark seem intended to suggest (PI §80). This can be connected with an earlier example in $§ 68$. Just as the absence of a rule for how high to throw a ball doesn't make tennis unplayable, so the absence of rules for the disappearance and reappearance of chairs doesn't make the "chair" languagegame unplayable. In both cases regularities of nature tend to take care of any problems with regard to this gap in rules, making it irrelevant. (For example, tennis players don't need to be stopped from playing time by pitching the ball so high it stays up orbiting the Earth, while chairs very rarely appear and disappear without explanation.) But now, what is the point of these examples and what is their connection with the discussion of family-resemblance concepts?

Based on what Wittgenstein says about the notion of family-resemblance in $§ 65 \mathrm{ff}$., we can characterize such concepts as follows. 1) The extension of a family-resemblance concept is determined by overlapping and criss-crossing similarities, kinships or affinities, rather than by anything common to all cases falling into the extension (PI §65-66). (Wittgenstein uses the terms "Ähnlichkeit" and 
"Verwandtschaft"; PI $\S \S 65-67,108$.) Accordingly, two instances might be connected directly by way of shared features or indirectly through other cases with which both cases share features without sharing any features between themselves (PI §67). 2) Consequently, family-resemblance concepts have open rather than closed boundaries in that new cases can be introduced into their extension without these cases having to share common features with all the old cases, and without their falling into the scope of a definition in terms of common features. New cases may thus extend the concept into new directions, and such additions can again constitute the basis for further extensions (PI $\S \S 68-69,76)$.

It's useful to compare these explanations with how Wittgenstein characterizes familyresemblance concepts in the context of earlier versions of the remarks on the colour-comparison, ethics and good. He writes in 1932-33:

What a concept-word indicates is certainly a kinship [Verwandtschaft] between objects, but this kinship need not be the sharing of a common property or a constituent. It may connect the members like links in a chain, so that one is akin [verwandt] to another through intermediary members. And two proximate members may have common features and be similar [ähnlich] to each other, while distant ones have nothing in common and yet belong to the same family. Indeed even if a feature is common to all family members it need not be that feature which defines the concept. (MS 140 p. 32 ; cf. PG p. 75; my square brackets)

The kinship between the members of a concept may be set up by the sharing of features which show up in the family of the concept, crossing and overlapping in very complicated ways.

Thus there is probably no single characteristic which is common to everything we call games. But it can't be said either that "game" just has several independent meanings (like for example the word "bank").What we call "games" are procedures variously akin to each other, with a multiplicity of transitions [Übergänge] between them. (MS 140 pp. 32-33; cf. PG pp. 75-76; my square brackets)

Two comments. Firstly, I interpret the first quote, according to which two cases that fall under a family-resemblance concept might be connected through an intermediary member, as making the same point as the Investigations which explains that cases falling under a concept might connected directly or 
indirectly. Both formulations allow for the possibility that there could be various indirect connections between cases through intermediate members. This explains what it means for similarities to crisscross, independently of the metaphor of similarities between family-members indicated by the word "family-resemblance". Secondly, although Wittgenstein continues to use the term "transition" in the Investigations to speak of other logical connections - for example, in the case of inferential relations or logical consequence and rule-following (PI $\S \S 187,189,486,534)$ - he largely stops using it in connection with family-resemblance. He doesn't employ it when introducing the notion of familyresemblance in the Investigations, unlike in the manuscripts and lectures from the early-mid 1930s. (See PI $\S 161$ for an exception.) Instead, the Investigations simply speaks of kinships and similarities between cases falling under a family-resemblance concept, that is, of specific kind of transitions between cases. Still, this corresponds to the earlier account in that, while according to MS 140 transitions between cases justify the view that were are dealing with a single concept, correspondingly the Investigations says it is "this kinship, or these kinships" between the cases on the basis of which we apply a single concept to them. (MS 140 p. 32; PI §65)

Further, the two characteristics of family-resemblance concepts - direct/indirect connections between cases and relatedness through similarities or kinships - seem to be what defines this mode of conceptual unity. While the feature of there being direct and indirect connections between cases explains the openness of their boundaries, the feature of there being kinships or similarities between the cases, distinguishes family-resemblance concepts from others that are not used according to definite rules or whose use isn't overall bounded by rules. For, obviously, the different possible definitions of "Moses" don't have similarity-based transitions between them that would justify our taking "Moses" as expressing a single concept. No similarity exists between a person being adopted by the daughter of a Pharaoh and a person leading a people out of slavery or passing on God's laws onto his people. Thus, although various transitions do exist between the different definitions of "Moses" - for example, he led his people out of slavery in the capacity of their leader - Moses isn't a family-resemblance concept. (Of 
course it's not ambiguous either. The different definitions of an ambiguous concept are not supports for a single concept. $)^{10}$

Relatedly, blurred concepts are not all family-resemblance concepts or similar to "Moses" in not being used according to definite rules. For example, the concept of baldness which has a blurred boundary does have something like a privileged definition relating to the absence of hair on the head, as opposed to a multiplicity of possible different definitions such as in the case of "Moses". As this indicates, Wittgenstein's interest in $§ \S 65-88$ isn’t blurredness as such. Rather, as I argue next, remarks $\S \S 65-83$ develop a methodological point regarding the employment of rules in philosophical clarification in cases where the use of words isn't regulated by definite rules or not regulated by rules overall. Here it's important to notice that although Wittgenstein's three examples, i.e. the open boundaries of family-resemblance concepts, the fluctuating uses of "Moses", and gaps or porosity in the rules for "chair", are quite different and might easily seem unrelated, the same methodological difficulty arises in all cases. This connects the examples, and enables us to make sense of why Wittgenstein discusses them together. Indeed, it seems revealing that his earlier remarks in MS 140 on this methodological point don't distinguish between the three different kinds of case.

Let me first discuss how the methodological problem is explained in Investigations $§ 81-83$, and then come to its earlier formulations. Here the core issue is expressed as follows: "[...] in philosophy we often compare the use of words with games, calculi with fixed rules, but cannot say that someone who is using language must be playing such a game.” (PI §81) In other words, albeit language might sometimes be helpfully compared with a calculus or a game according to rules, it cannot be claimed, pace Tractatus, that there is a single underlying system of logical rules which any possible thinker or speaker must abide by in order to count as thinking/speaking. Or more weakly, it cannot be claimed that a person's use of particular words as the expression of specific concepts must conform to such and such rules without running the risk of dogmatic falsification of the use (PI $\S \S 130-131) .{ }^{11}$ Wittgenstein then goes on immediately to note two problematic ways of developing the account of philosophical or 
logical clarification in response to this point. For example, we might conclude that logic provides us with an idealized account of language use comparable to idealized accounts in physics, leaving out features to be filled in later on. Alternatively, if we say that logic constructs ideal languages with the purpose of clarifying actual language use, it may appear that such ideal languages would be closer to some ideal of logical perfection. Both accounts are rejected by Wittgenstein as problematic, however. (PI §81; cf. MS 140 p. 33; MS 115 pp. 45-47) ${ }^{12}$

This leads us to how the problem and its solution are described in $\S \S 82-83$, followed by comments on the notions of rule and exactness in $\S \S 84-88$. Wittgenstein writes on describing the use of a word as according to a rule, referring also back to the example of " $\mathrm{N}$ ":

What do I call 'the rule according to which he proceeds'? - The hypothesis that satisfactorily describes his use of words, which we observe; or the rule which he looks up when he uses signs; or the one which he gives us in reply if we ask him what his rule is? - But what if observation does not clearly reveal any rule, and the question brings none to light?

For he did indeed give me an explanation when I asked him what he meant by "N", but he was prepared to withdraw this explanation and alter it. - So how am I to determine the rule according to which he is playing? He does not know it himself. - Or, more correctly: What is left for the expression "the rule according to which he proceeds" to say? (PI $\S 82 ;$ cf. $§ 54)$

According to Wittgenstein there are thus several senses in which one might speak of a rule that someone follows: 1) an observed regularity, 2) a rule consulted in using the word (or also teaching its use, see PI §54) and 3) a rule of which the speaker informs the observer. But if the rule according to which someone proceeds cannot identified in any of these ways, is there any further sense left in which we could speak of a rule here? "What is left for the expression "the rule according to which he proceeds" to say?' The next remark explains:

Doesn't the analogy between language and games throw light here? We can easily imagine people amusing themselves in a field by playing with a ball like this: starting various existing games, but playing several without finishing them, and in 
between throwing the ball aimlessly into the air, chasing one another with the ball, throwing it at one another for a joke, and so on. And now someone says: The whole time they are playing a ball-game and therefore are following definite rules at every throw.

And is there not also the case where we play, and make up the rules as we go along? And even where we alter them as we go along. (PI §83)

Wittgenstein's methodological point can now be outlined. Although a description of language use according to rules must describe it as used according to certain definite rules - since otherwise the description is indeterminate - it's not a requirement for the possibility of describing language in terms of rules that it should be used according to any definite rules. As the remark explains, even though players or speakers might constantly keep changing the game, or making the rules up as they go, it's still possible to describe what they are doing as conforming to definite rules. Wittgenstein comments on this when drafting the points in $\S 81$ and $\S 83$ : “[...] while it's possible to give a rule for every action [move] which it corresponds to, we must in certain cases describe the use of language as a continuous change of the game (schedule of rules) [...]. So that we must say we view language in the form of a game, of acting according to a schedule of rules.” (MS 112 pp. 95r-v; cf. TS 211 p. 492)

Rather than involving any claims about language as actually used according to such and such rules or that is must be used according to them (PI §81), Wittgenstein's methodological suggestion therefore is to describe language in terms of rules in the sense of comparing it with a game according to definite rules. The rules then constitute the describer's mode of representing language, rather than the object of investigation of which a metaphysical or empirical true/false claims or theses are made. ${ }^{13}$ As the Investigations sums up the point later, with reference to simple language-games as models for language use (repeating also the point from $\S 81$ that such models are not idealizations whose details are to be filled in later) simple language-games are to be used "[...] as objects of comparison which, through similarities and dissimilarities, are meant to throw light on features of our language” (PI §130). 
Consider now the MS 140 version of the remark on ethics and good and its explanation of the same methodological point:

If we look at the actual use of a word, what we see is something constantly fluctuating.

In our investigations we set over against this fluctuation something more fixed, just as one paints a stationary picture of the constantly altering face of the landscape.

When we study language we observe it from the point of view of a game with fixed rules. We compare it with, and measure it against, a game of that kind.

If for our purposes we wish to regulate the use of a word by definite rules, then alongside its fluctuating use we set up a different use by codifying in terms of rules one of its characteristic aspects.

Thus it could be said that the use of the word "good" (in an ethical sense) is a combination of a very large number of interrelated games, each of them as it were a facet of the use. What makes a single concept here is precisely the connection, the kinship, between these facets. (MS 140 p. 33/PG p. 77)

Now, Wittgenstein's view may indeed be that the concept of good is a family resemblance concept, as I argue in the next section. Evidently, however, he is not concerned in this remark to distinguish familyresemblance concepts from other fluctuating uses, where language isn't used according to definite rules or isn't bound by rules overall. Plausibly, the explanation isn't carelessness, but that the difference doesn't matter for the methodological point he wishes to make. In all three kinds of cases we can capture characteristic aspects or facets of the use in rules. More specifically, whilst in the case of family-resemblance concepts we may understand by such aspects the different kinds of cases that fall under the concept, such as natural and irrational numbers which both have their own definitions, in cases such as "Moses" we might describe the different definite descriptions given to explain the concept as constituting different aspects or facets of use. But since here, by contrast to familyresemblance, there are no similarities between the different cases, the notions of aspect or facet have slightly different meanings in the two cases. 
The comparison of concepts with blurred colour patches can now be explained. As the preceding quote from MS 140 emphasizes, Wittgenstein's descriptions of language use in terms of rules serve a specific purpose, i.e. philosophical clarification (cf. also the following quote from MS 140). Importantly, the goal of philosophical clarification can trump empirical accuracy as a goal of describing language use in that the two tasks have different criteria of success and justification. For example, philosophy might require one to draw sharp distinction where no clear distinction is marked in actual use of natural language. Thus, whether one should draw, for example, a rectangle or a heart in order to mark the borders of a blurred concept isn't arbitrary, contrary to what focusing on the blurredness of the actual concepts alone may suggest (PI §77). An example is the distinction between logical or grammatical rules and statements of fact, which plays a crucial role in both Wittgenstein's early and later philosophy, but doesn't have similar importance in everyday life. Relatedly, it's not uncommon that in natural language one and the same expression is used to express a statement of rule (for instance a definition) and an empirical factual statement, as exemplified by "This is one meter long", "Men are mortal", and so on. Indeed, Wittgenstein suggests that unclarity about the distinction between factual statements and logical or grammatical rules plays a crucial role in the idea - according to him, a confused one - that there should be a discipline such as metaphysics whose statements simultaneously possess exceptionless generality (universality) and constitute true/false statements about reality. (RPP I §549; see see Kuusela, 2008, Chapter 3 for discussion). In MS 140 the colour patch comparison is explained in just these terms:

But if we wish to draw boundaries in the use of a word, in order to clear up philosophical paradoxes, then alongside the actual picture of the use, in which as it were the different colours flow into one another without sharp boundaries, we may put another picture which is in certain ways like the first but is built up of colours with clear boundaries between them. (MS 140 p. 32; cf. PG p. 76) 
I hope to have now made it plausible that in Investigations $\S 77$ and the surrounding remarks $\S \S 65-83$ Wittgenstein is concerned with a methodological issue of general import, rather than a claim or thesis about good as a family-resemblance concept. Similarly, his earlier remarks in MS 140 make a methodological point, as indicated by the fact that he doesn't see the need there to distinguish between different kinds of concepts to which the point applies. Indeed, as Wittgenstein's formulation indicates, he doesn't wish to make any claims in MS 140 about the unity of concepts such as game: "[...] there is probably [wohl] no single characteristic which is common to all the things we call games." (MS $140 \mathrm{p}$. 32/PG p. 75; my italics) Similarly, it's plausible that his purpose in the Investigations isn't to make claims about the unity of any specific concepts. All that is required to motivate Wittgenstein's methodological proposal is that it's not necessary for concepts to have the kind of simple unity that allows them to be defined in terms of a single overarching definition in terms of common features. If simple unity isn't a necessary feature of concepts, and it cannot be taken for granted, then there is clearly a need for the kind of modification of philosophical methodology that Wittgenstein proposes. In this sense his methodological proposal doesn't depend on any claims about whether language, game, mathematics or good actually are family-resemblance concepts. Instead, Wittgenstein only needs to make plausible the possibility that concepts such as language, game or mathematics are familyresemblance concepts. This explains his seemingly relaxed attitude in the Investigations towards arguing that relevant concepts actually are family-resemblance concepts. Surely, his "demonstration" would otherwise be half-hearted at best. ${ }^{14}$

In conclusion to this section, it's important that the method Wittgenstein outlines isn't only applicable to blurred concepts, as exemplified by his three examples. It's more broadly applicable to any concepts with complex unity, as illustrated by psychological concepts many of which involve a distinction between first-person and third-person uses, as exemplified by the possibility of expressing or manifesting one's own pain, but not that of another, although, according to Wittgenstein, it's possible to know that another is in pain ( $\mathrm{Z} \S 472$; PI $\S \S 244,253,293,304)$. Here too it's natural to 
speak of aspects of facets of use which constitute a single concept, even though pain isn't, on this account, a family-resemblance concept. The method thus has further applications which Wittgenstein isn’t yet in a position to explain in $\S \S 65-83$. At this point psychological concepts have not yet been discussed in the Investigations.

But let us now return to the concept of good. In the concluding section I discuss Wittgenstein's remarks on the concept of good, whether he regards good as a family-resemblance concept, and how his methodological proposal can help us to develop a more complex account of good than traditional moral philosophical theories allow for, as outlined in section 1. Arguably, this can help to make progress with the question of the unity of good.

\section{Wittgenstein and the unity of good: Stocker's and Williams's criticisms in perspective}

As argued, it's implausible that Wittgenstein intends to make claim about the unity of good either in the Investigations or MS 140. Rather, he uses "good" as an example in making a more general methodological point. Possibly, he also wants to designate ethics as an area where his proposed method could be advantageously applied, but which he himself doesn't discuss in a systematic way. Wittgenstein does make relevant remarks on good elsewhere, however, and in his lectures in 1932-33 he speaks of good in terms that indicate that he does consider it a family-resemblance concept. For instance, he describes the instances of good as connected through similarity-based transitions, rather than through common features. On the preceding basis this can be understood as a description of good as a family-resemblance concept, as opposed to some other kind of concept with complex unity. The following quote can additionally be taken to confirm that when speaking of good in the Investigations, Wittgenstein intends to make a heuristic point, not one subject to the genetic fallacy.

In view of the way we have learned the word "good" it would be astonishing if it had a general meaning covering all of its applications. I am not saying it has four or five different meanings. It is used in different contexts because there is a 
transition between similar things called "good", a transition which continues, it may be, to things which bear no similarity to earlier members of the series. We cannot say "If we want to find out the meaning of 'good' let's find what all cases of good have in common". They may not have anything in common. The reason for using the word "good" is that there is a continuous transition from one group of things called good to another. (AWL p. 33)

Accordingly, Wittgenstein speaks of there being resemblances between different instances of good which constitute a family, noting also how this creates a problematic situation in philosophy due to the tendency of philosophers to look for definitions in terms of common features. A dictation to students from 1935 explains:

What I have said here applies also to words like "good" and "beautiful". There is nothing identifiably in common to the states of affairs for which we use a word. There is only a number of overlapping resemblances. Our concepts are enormous families with various resemblances. One of our main philosophical troubles, which constantly recurs, is that we have such a family. We want to get clear about the use of a word, and so we hunt for something common to the instances the word applies to, even when there is hardly anything in common. (AWL p. 96; cf. p. 34)

These two quotes, I take it, suffice to show that Wittgenstein did understand good as a familyresemblance concept in the early-mid 1930s. Nothing suggests that he changed his mind later on. Thus, Klagge seems right in the dispute between Hacker and von Wright. ${ }^{15}$ But this as such doesn't get us very far in understanding or characterizing the concept of good. This point about unity doesn't yet tell us anything about how the word "good" is used, what the different members of this family are, and how they relate to one another (except formally, by means of similarities). As Wittgenstein remarks in another connection, concluding that a concept is indefinable or lacks an overarching definition doesn't yet solve any philosophical problems (see PI §182). More specifically, he remarks on good when discussing the remembering of sensations: "But the word "specific" (or an analogous one), which one would very much like to use here, does not help. It is as little of a resource as the word "indefinable" when one says that the word "good" is indefinable. $\$ What we want to know, to get an overview of, is 
the use of the word "good”, [...].' (RPP I §160) In attempting to progress towards philosophical clarity about the concept of good, we might then advantageously follow Wittgenstein's heuristic suggestion in Investigations $\S 77$. Although a detailed discussion of this issue is beyond the scope of this article, I conclude with some comments on this, and how the proposed method could help us to find a way forward in moral philosophy beyond the stalemate between the main competing theories.

One way in which children are taught the use of "good" is by adults directing them to do good actions and to avoid bad ones. For example, a child might be instructed to let another one play with her toys - a type of action that might be seen as a prototype for generous actions -, and that she should not take toys from others against their will - a prototype for actions that show consideration and respect for others. Here it seems right to say with Aristotle that when a child acts as instructed she isn't yet doing a good action (NE pp. 1105a-b). Indeed, insofar as Aristotle and Kant are right that a good action must be done knowingly and from the right kind of motive, then good actions don't seem possible to a small child. Of course, this might leave one wondering how to describe the action of a small child who comforts a tired parent or a hurt sibling. Regardless of that, however, in these examples we can find the beginnings of (what we can call) agent-and-action-centred language-games with "good" that involve the goal of doing what is good and/or right, and in their mature form involve questions about the agents motives, for instance, whether the action was done in order to do something good or merely in order to appear to be doing something good.

Another importantly different but connected language-game relates to good states of affairs which the child isn't involved in bringing about but which are recognized as good, for instance, that all is well in the kingdom after the evil witch has been defeated. (I'm assuming that fairy tales play an important role in teaching a child about good and bad by means of cases beyond the child's own experiences.) With regard to moral philosophical theories, this language-game is emphasized by the utilitarians. Indeed, as one might say with Aristotle and Kant, utilitarians emphasize this languagegame at the expense of the agent-and-action-centred games in that from a utilitarian point of view the 
goodness of actions simply depends on the state of affairs brought about. Thus, unlike Aristotle and Kant, utilitarians may accept as good even actions that produce something good by accident, and they don't similarly recognize the importance of moral agents' knowledge and motives for the goodness of actions.

My reason for highlighting these two language-games with "good" (without any claim that they are the only ones and that other distinctions could not be drawn) is that distinguishing between them can establish a philosophically helpful perspective on certain issues in moral philosophy. I have in mind the well-known criticisms of utilitarianism by Bernard Williams and Michael Stocker which can be used to briefly illustrate how Wittgenstein's heuristic suggestion in the Investigations might help us, although this is necessarily a mere sketch. To sum up some of Williams' and Stocker's points, contrary to utilitarianism, good actions cannot always be understood as such on the basis of the good states of affairs they bring about. Even if bringing about a relevant state of affairs would be considered one's duty, such a duty cannot always explain the goodness of one's action. Rather, sometimes the agent's motive is essential to the goodness of action in that the action cannot be understood as exhibiting the goodness of, for instance, friendship, love or care, without the right kind of motive. As illustrated by Stocker's example of visiting a friend in a hospital, an action that exhibits the good of friendship cannot be motivated by the maximization of utility; insofar as the action was motivated by a desire to maximize utility, it cannot be understood as having been done out of friendship (Stocker, 1976 p. 462). The same goes for a morally good action of love or care, as when saving one's own wife from drowning at the expense of someone else. As Williams famously notes, the husband who reminds himself that a partial action to save one's wife is permissible or even a utilitarian duty, since actions of taking care of close ones are generally utility maximizing, has "one thought too many" (Williams, 1981 p. 18). Insofar as this utilitarian justification motivates the husband (is his reason for action), the action isn't one of caring and loving. Relatedly, as Williams points out, utilitarianism fails to recognize moral goods such as integrity, insofar as utilitarianism requires an agent to simply act in order to bring about a 
morally good, or less bad, state of affairs. This is exemplified by the botanist Jim who supposedly has the utilitarian duty to save 19 persons by personally killing one, merely because he happens to find himself in a situation where 20 will otherwise be killed (Williams, 1973 p. 99). So, if Stocker and Williams are right, the goodness of an action cannot always be explained by the goodness of the state of affairs it brings about (or with reference to a duty to bring about such a state of affairs), and there are goods, such as integrity, that cannot be recognized as goods from this state-of-affairs-centred perspective.

My point is the following. Wittgenstein's suggestion that good has a complex unity, and his point that we can start clarifying the different uses of "good" by examining cases in which children learn its use, can put into helpful perspective criticisms such as those of Stocker and Williams, as well as Aristotle's and Kant's emphases on motivation and acting knowingly. We can now see these points as raised from the direction of agent-and-action-centred language-games and, correspondingly, clarify the problem with utilitarianism by describing it as attempting to explain all moral uses of "good" reductively from the point of view of the state-of-affairs-centred language-game with "good". However, if good does have a complex unity with different facets of use, such as the agent-and-actioncentred and state-of-affairs-centred language-games, such reductive attempts to explain the unity of good are not going to work. The same goes for explaining the goodness of states of affairs in terms of good actions in that a good state of affairs cannot simply be understood as one produced in the right way (with appropriate motives and knowingly). In this way Wittgenstein's account of the unity of good can help to put moral philosophical disputes into a broader perspective, and help us to address disputes and the problems in moral philosophy. Consequently, from this perspective we might be able to explain the correctness of points made by different moral philosophical parties by limiting their scope to those language-games from the point of view of which they are made. As Wittgenstein comments on Augustine's account of meaning in terms of reference, when introducing the method of languagegames, "You can rectify your explanation by expressly restricting it to those games" (PI §3). 


\section{Conclusion}

In the last section I outlined one way in which Wittgenstein's methodological considerations might help to find a way forward in moral philosophy. But of course considering how a concept is learned is not the only way in which Wittgenstein's methodology for dealing with complex concepts can help. More generally, he can be read as suggesting that we can use simplified models, such as simple language-games, but also other means of clarification such as Wittgensteinian grammatical rules, to clarify specific aspects of complex moral concepts. As explained in section 3 , we are to compare the actual fluctuating uses of language with simpler models, such as language-games with definite rules, in order to clarify specific facets of the actual uses. (For Wittgenstein's methods more generally, see Kuusela 2019b.) However, among such models we might also include the Aristotelian, Kantian and utilitarian theories (perhaps stripped of some of their features and commitments). Their mistake then isn't that they say nothing helpful about goodness. It's rather that each theory claims to explain everything essential about moral good, whilst their assumption of the simple unity of good gives reasons to doubt they can achieve this, as indicated by the stalemate between them. If, however, we "rectify those eplanations by expressly restricting them" to the games with "good" that the theories can clarify, it seems that we can move away from the stalemate towards a truer account of moral goodness. What emerges is a more piecemeal Wittgensteinian moral philosophy, where we approach moral philosophy, not by putting forward an allegedly exclusively correct theory that is claimed to explain all instances of moral good. Rather, we seek to clarify the different aspects or moral good by means of a variety of more specific models, perhaps in connection with more specific issues such as what the goods of friendship or integrity involve, and also with reference to specific moral problems, gradually working towards a better grasp of the whole. It might now be objected that this doesn't allow us to do justice to the aspiration of the Kantian and utilitarian theory to offer action guidance through their 
principles. However, if moral good has a more complex unity than these theories admit, as indicated by the objections of Stocker and Williams, then the Kantian and utilitarian theories cannot offer reliable action guidance anyway. If so, we might do better by trying to find action guidance through more piecemeal considerations, such the Wittgensteinian approach can provide. ${ }^{16,17}$

\section{Bibliography}

Al Zoubi, O. (2016). "Wittgenstein and Family Concepts", Nordic Wittgenstein Review 5, 31-54.

Aristotle. (1996). Eudemian Ethics: Books I, II and VIII. Oxford: Oxford University Press. (EE)

Aristotle. (2000). Nicomachean Ethics. Cambridge: Cambridge University Press. (NE)

Baker, G. and Hacker, P.M.S. 2005. Wittgenstein, Understanding and Meaning: Volume I of An Analytical Commentary on the Philosophical Investigations. Oxford: Wiley-Blackwell.

Diamond, C. (1996). "Wittgenstein, Mathematics, and Ethics: Resisting the Attraction of Realism”. In H. Sluga and D. Stern (Eds.), The Cambridge Companion to Wittgenstein. Cambridge: Cambridge University Press.

Glock, H-J. (1996). A Wittgenstein Dictionary. Oxford: Blackwell, 1996.

Forster, M. (2010). "Wittgenstein on Family Resemblance Concepts". In A. Ahmed (Ed.), Wittgenstein's Philosophical Investigations: A Critical Guide. Cambridge: Cambridge University Press. Kant, I. (1997). The Groundwork of the Metaphysics of Morals. Cambridge: Cambridge University Press.

Klagge, J. (2018). "Wittgenstein and von Wright on Goodness", Philosophical Investigations 41, 291303.

Kuusela, O. (2008). The Struggle against Dogmatism: Wittgenstein and the Concept of Philosophy. Cambridge, MA: Harvard University Press. 
Kuusela, O. (2014). "The Method of Language-games As a Method of Logic”. Philosophical Topics $42,129-160$.

Kuusela, O. (2019a). "Logical-Linguistic Method in Moral Philosophy: Solving Problems from Murdoch and Williams with Wittgenstein”. In B. De Mesel and O. Kuusela (Eds.), Ethics in the Wake of Wittgenstein. New York: Routledge.

Kuusela, O. (2019b). Wittgenstein on Logic as the Method of Philosophy; Wittgenstein's Philosophy of Logic in Relation to Frege, Russell, Carnap, and Others Oxford: Oxford University Press.

Kuusela, O. (forthcoming). "Diamond and the Subject Matter of Ethics". In M. Balaska (Ed.), Cora Diamond on Ethics. Houndmills: Palgrave-McMillan.

Mill, J. S. (1998). "Utilitarianism”. In On Liberty and Other Essays, Oxford: Oxford University Press. Mulhall, S. (2002). "Ethics in the Light of Wittgenstein”, Philosophical Papers 31, 293-321.

Richter, D. (2018). "Sketches of Blurred Landscapes: Wittgenstein and Ethics”. In E. Dain and R. Agam-Segal (Eds.), Wittgenstein's Moral Thought. New York: Routledge.

Russell, D. (2010). "Virtue and Happiness in the Lyceum and Beyond", Oxford Studies in Ancient Philosophy, 38, 143-185.

Sluga, H. (2006). "Family Resemblance”, Grazer Philosophische Studien 71, 1-21.

Sluga, H. (2011). Wittgenstein. Oxford, Wiley-Blackwell.

Søndergaard-Christensen, A.-M. (2018). “What Is Ethical Cannot Be Taught” - Moral Theories as Descriptions of Moral Grammar". In E. Dain and R. Agam-Segal (Eds.), Wittgenstein's Moral Thought. New York: Routledge.

Stocker, M. (1976). "The Schizophrenia of Modern Ethical Theories”, Journal of Philosophy, 73, 453466.

Waismann, F. (1960). "Verifiability". In A Flew (Ed.), Logic and Language (First Series). Oxford: Blackwell. 
Williams, B. (1973). “A Critique of Utilitarianism.” In J.J.C. Smart and B Williams (Eds.), Utilitarianism for and against. Cambridge: Cambridge University Press.

Williams, B. (1981). "Persons, Character and Morality." In Moral Luck: Philosophical Papers 19731980. Cambridge: Cambridge University Press.

Wittgenstein, L. 1951. Tractatus Logico-philosophicus. London: Routledge \& Kegan Paul. (TLP)

Wittgenstein, L. (1967). Zettel. Oxford: Blackwell. (Z)

Wittgenstein, L. (1974). Philosophical Grammar. Oxford: Blackwell. (PG)

Wittgenstein, L. (1980). Remarks on the Philosophy of Psychology, Vol 1. Oxford: Blackwell. (RPPi)

Wittgenstein, L. (1998). Remarks on the Foundations of Mathematics Oxford: Blackwell. (RFM)

Wittgenstein, L. (2000). Wittgenstein's Nachlass: The Bergen Electronic Edition. The Wittgenstein Archives at the University of Bergen eds. Oxford: Oxford University Press.

Wittgenstein, L. (2009). Philosophical Investigations, Revised Fourth Edition. Oxford: WileyBlackwell. (PI)

Wittgenstein, L. (2016). Lectures, Cambridge 1930-1933: From the Notes of G.E. Moore, David Stern, Brian Rogers and Gabriel Citron eds. Cambridge: Cambridge University Press. (MWL) Von Wright, G.H. (1963). The Varieties of Goodness. London: Routledge.

\footnotetext{
${ }^{1}$ See von Wright 1963 p. 14 for problems with explaining the varieties of goodness in terms of ambiguity.

${ }^{2}$ See Russell 2010 for discussion of the contribution of virtue and external goods to Eudaimonia. Thanks to Catherine Rowett for discussion of the interpretive possibilities.

${ }^{3}$ If analogical explanations are not assumed to involve a primary case and extensions, but instances of goodness are regarded along the lines of "gills are to fishes what lungs are to humans", whereby neither case is regarded as primary, von Wright's argument doesn't seem to work, and the analogical model of unity might merit more consideration after all. Thanks to Catherine Rowett for pointing out this different way of understanding the notion of analogy.

${ }^{4}$ Klagge's view could be described as the standard one, with for example Glock (1996 p. 109), Forster (2010 p. 68) and Richter (2018 pp. 166-167, 169) holding this view.
} 
${ }^{5}$ Forster argues that family-resemblance doesn’t imply indeterminacy of extension, and so blurredness of boundaries isn’t essential to family-resemblance (Forster, 2010 p. 70). This seems correct in that, whilst different kinds of numbers may be considered as constituting a family, each kind may have a precise definition (see section 3). Nevertheless a familyresemblance concept can have blurred boundaries, as exemplified by the concept of art. The openness or extensibility of the borders of family-resemblance concepts also indicates their potential extensional indeterminacy, which may explain why Wittgenstein doesn't emphasize the point Forster makes. Pace Forster, this might therefore not be a confusion or mistake on Wittgenstein's part.

${ }^{6}$ I will discuss such cases in section 4. By contrast, Hacker expresses doubts about whether this is a useful suggestion, as well as assuming that Wittgenstein is speaking of learning the use of the word good in general, including its non-moral uses (Hacker, 2005 p. 169). As will be clear from section 4, I disagree with Hacker on the usefulness of Wittgenstein suggestion. ${ }^{7}$ Klagge (2018 p. 292) lists PI $§ 77$ as one of three remarks that constitute the "main evidence" for Wittgenstein’s view of good as a family-resemblance concept. Clearly this evidence is weak, however, insofar as Wittgenstein's point isn't to make a claim about the unity of good specifically.

${ }^{8}$ This suggests, although Wittgenstein doesn't say so explicitly, that different kinds of concepts could be regarded as constituting a family, and that the concept of a concept is a family-resemblance concept. Elsewhere Wittgenstein characterizes the concept of a concept as vague (MS 124 p. 147/RFM VIII §45).

${ }^{9}$ Waismann coins the term "open texture" for such concepts (1960 p. 119).

${ }^{10}$ It is a debated question, whether Wittgenstein regards family-resemblance concepts as unified by similarities or also by other relations, including causal relations, such as exist in a family. Although I cannot discuss this in detail, I find no justification in Wittgenstein's texts for taking him to be speaking of family-resemblance in the sense of causal connections that would explain why certain similarities rather than others are relevant for certain family-resemblance concepts. Indeed, such causal explanations wouldn't be consistent with Wittgenstein's rejection of explanations of concept formation in terms of empirical natural history that would explain why we have certain concepts rather than others (PI II, xii/PPF $\S 365-367$ ). Relatedly, Wittgenstein comments on the issue that there are transitions from anything to anything, and so transitions don't seem to determine any definite concept: "By knowledge we mean such and such procedures and similar ones" (MS $140 \mathrm{p}$. 32). It's thus assumed in the description of family-resemblance that concept users would have a grasp of relevant similarities. This isn't anything to be explained in the (quasi-)scientific manner that Wittgenstein excludes. For an overview of debates on family-resemblance, where this distinction between logical description and (quasi)-scientific explanation has been largely ignored, see Al Zoubi 2016. Sluga argues that family-resemblance is partly explained in causal kinship terms or in terms of relations of origin, and that Wittgenstein runs together such terms with similarity terms in his account of family- 
resemblance (2006 p. 14; cf. Sluga, 2011, Chapter 5.). However, I fail to see how his discussion establishes that Wittgenstein commits any such mistake and, consequently, how it's relevant for Wittgenstein's account of familyresemblance that family-membership in human families isn't established on the basis of mere similarities, and that there may be something like kinship concepts determined by genealogical relations. See Kuusela, 2019b, Chapter 6 for discussion of the ways in which empirical considerations can be relevant for logic on Wittgenstein's later philosophy of logic.

${ }^{11}$ For discussion of this problem and the dilemma of injustice/emptiness it gives rise to, see Kuusela, 2008 pp. $111 \mathrm{ff}$.

${ }^{12}$ Although space doesn't allow me to discuss the problems with these accounts, they can be quickly outlined. In effect, the first account would imply the postponement of the clarification of philosophical problems, with a rough idealized account offered instead, and proper clarification deferred to the future. Moreover, it's unclear how an idealized philosophical account ought to be completed, since what the account needs to include depends on our questions and unclarities regarding the issue, but it's not possible to determine in advance what problems might be raised about an issue. Further problems can always be raised or imagined. The second account is problematic in that it's unclear what the criterion is for saying that the ideal languages of logicians would be better than natural languages. For discussion, see Kuusela, 2019b, Chapter 4.

${ }^{13}$ The question might be raised what the importance of Wittgenstein's concern with rule-following is in the Investigations, if his method doesn't involve commitment to a view language being used according to definite rules. Although this issue is beyond the scope of this paper, it's important that Wittgenstein explicitly rejects rule-following as a foundational concept that must be accounted for in order to justify descriptions of language use according to rules (MS 114 p. 104/PG pp. 115116; see MS 111 p. 110; TS 213 p. 67; MS 116 pp. 57-58). This is an important aspect of his later approach, with Wittgenstein rejecting the kind of hierarchical organization of philosophy assumed in the Tractatus, where an account of the nature of proposition and language as a calculus play a relevant kind of foundational role. Rather than through such a foundational thesis, the comparison between language and games according to rules, and descriptions of specific uses in terms of rules are justified through the clarificatory work they can do. Nevertheless, this doesn't mean that the concept of rule-following wouldn't be important to clarify for a variety of reasons relating, for instance, to Wittgenstein's account of meaning as use, sometimes but not always cashed out in terms of rule-governed use, his concerns with logic and the philosophy thereof, philosophy of mathematics and so on. See Kuusela, 2008 pp. $218 \mathrm{ff}$.

${ }^{14}$ On this point I disagree with Sluga who takes the task of Wittgenstein's discussion of family-resemblance to be to establish that “"language” is a family resemblance term' (Sluga, 2006 p. 5).

${ }^{15}$ Hacker also argues that Wittgenstein view of good as a family-resemblance concept is "unconvincing", because unlike in the case of art, where new forms of art have emerged over history, new forms of goodness don't seem to have emerged (Hacker, 2005 p. 171). As Klagge notes, it's not very clear what Hacker means by new forms of goodness, and he is merely 
asserting rather than arguing for his point (Klagge, 2018 pp. 293-296). I agree with Klagge, but woud like to add one consideration, even though it's connected with larger issues that I don't have the space to discuss (see Kuusela, forthcoming). Hacker's criticism doesn't take into account that according to Wittgenstein "good" is applied to cases on the basis of their non-moral features, for example, that an action involved risking one's life in order to help someone. It then depends on such features, which according to Wittgenstein are constitutive of an action's goodness, what goodness is in a particular case more precisely. "The way in which you use "good" in particular case is partly defined by the topic you're talking of. $\backslash \backslash$ Each way in which A can convince B that $\mathrm{x}$ is good, fixes a meaning in which "good" is used - fixes the grammar of the discussion.' (MWL p. 325; cf. AWL p. 33) Or to explain the point by means of Wittgenstein's analogy between beauty and good, just as beauty is something different in the case of a song and a face, so two actions may be good in different senses (AWL pp. 35-36). For example, the goodness of a kind and a brave action or two different kinds of brave actions might differ in this way. (Consider the difference between a non-violent brave action and a brave action of a war hero. Whilst the first one can be associated with peacefulness, and a range of other good actions that exhibit peaceful determination, the latter cannot. Thus, although both actions are brave, they seem to be brave in different senses, with transitions from them to different further cases.) Against this background the emergence of new forms of goodness seems to become comprehensible. But it only means that in new circumstances new kinds of actions become possible, and they might exhibit goodness in novel ways. For example, the progress of medicine can create such situations. Perhaps Socrates would have been an organ donor, but this kind of good action was not available to him. Here it's not obvious how or that the goodness of this action can be explained as being the same as the goodness of actions that were available to Socrates. Organ donation isn't generosity, for instance, and generous actions might themselves constitute a family, so that reductive explanations of this kind might not bring us any further. But whoever may be right, it's possible to respond to Hacker's criticism.

${ }^{16}$ For further discussion of how the Wittgensteinian approach can help to solve problems raised for moral philosophy, see Kuusela, 2019a, and Søndergaard-Christensen, 2018. I take my discussion to be compatible with the latter's outline of a Wittgensteinian moral philosophy, although her discussion proceeds at a more general level. Further, certain Wittgenstein's readers have argued for continuity between Wittgenstein's early and later account of ethics with respect to his early rejection of substantial ethical concepts and judgments, suggesting that moral philosophy cannot be understood as a discipline with specific subject matter that can be identified in terms of distinctively moral concepts, such as goodness (Diamond, 1996 and Mulhall, 2002). I would like to express cautious agreement with this view, although space doesn't allow a proper discussion. If goodness isn't a specific quality, as Wittgenstein says (MWL p. 333), and it's spoken of in many senses, whereby the non-moral features of an action determine the sense in which an action is good (cf. endnote 15), 
then then there doesn't seem to be a subject matter for moral philosophy that could be identified in terms of distinctively moral concepts alone. Rather, the use of moral concepts is embedded into the use of non-moral concepts, and it may sometimes be possible to express moral considerations without making use of distinctively moral concepts at all, as Diamond argues.

${ }^{17}$ I would like to thank Catherine Rowett for comments on a draft version, and the audiences at two conferences, Wittgensteinian Approaches to Moral Philosophy (Third Edition) in Leuven, and Alternative Contemporary Ethics in Rome, both in September 2017. 